\title{
Glycemic control in acute illness
}

\author{
Korean Journal of Anesthesiology Moritoki Egi, Nana Furushima, Shohei Makino, and \\ Satoshi Mizobuchi
}

Department of Anesthesiology, Kobe University Hospital, Kobe, Japan

Hyperglycemia is commonly observed in critical illness. A landmark large randomized controlled trial (RCT) reported that the incidence of hyperglycemia (blood glucose concentration $>108 \mathrm{mg} / \mathrm{dl}$ ) was as high as $97.2 \%$ in critically ill patients. During the past two decades, a number of RCTs and several meta-analyses and network meta-analyses have been conducted to determine the optimal target for acute glycemic control. The results of those studies suggest that serum glucose concentration would be better to be maintained between 144 and $180 \mathrm{mg} / \mathrm{dl}$. Although there have been studies showing an association of hypoglycemia with worsened clinical outcomes, a causal link has yet to be confirmed. Nonetheless, some researchers are of the view that the data suggest even mild hypoglycemia should be avoided in critically ill patients. Since acutely ill patients who receive insulin infusion are at a higher risk of hypoglycemia, a reliable devices for measuring blood glucose concentrations, such as an arterial blood gas analyzer, should be used frequently. Acute glycemic control in patients with premorbid hyperglycemia is a novel issue. Available literature suggests that blood glucose concentrations considered to be desirable and/or safe in non-diabetic critically ill patients might not be desirable in patients with diabetes. Moreover, the optimal target for acute blood glucose control may be higher in critically ill patients with premorbid hyperglycemia. Further study is required to assess optimal blood glucose control in acutely ill patients with premorbid hyperglycemia.

Key Words: Acute illness, Diabetes mellitus, Glucose, Glucose measurement, Hyperglycemia, Insulin.

\section{Stress-induced Acute Hyperglycemia}

Hyperglycemia is commonly observed in critical illness. It was reported that increased blood glucose concentrations of more than $108 \mathrm{mg} / \mathrm{dl}$ were observed in $97.2 \%$ of critically ill patients [1]. This trial also showed that blood glucose concentrations exceeded $180 \mathrm{mg} / \mathrm{dl}$ in $69.0 \%$ of the patients in this cohort.

Acute illness has been reported to be accompanied by a hy-

Corresponding author: Moritoki Egi, M.D.

Department of Anesthesiology, Kobe University Hospital, 7-5-2 Kusunokicho Tyoku, Kobe, Japan

Tel: 81-783825111, Fax: 81-783826172

Email: moriori@tg8.so-net.ne.jp

ORCID: https://orcid.org/0000-0002-0099-3060

Received: October 19, 2017.

Revised: October 31, 2017.

Accepted: November 10, 2017.

Korean J Anesthesiol 2017 December 70(6): 591-595

https://doi.org/10.4097/kjae.2017.70.6.591 permetabolic state [2] due to the release of cytokines and counter-regulatory hormones [3]. A hypermetabolic state induces insulin resistance and increases hepatic glucose production (gluconeogenesis), resulting in acute hyperglycemia [4,5]. Acute hyperglycemia was reported to be more pronounced with the use of glucose-containing infusions [3], sympathomimetic drugs and corticosteroids [6]. Acute hyperglycemia was shown to be associated with poor outcomes and thus might be a marker of the severity of illness [7-12]. Two decades ago, it was believed that the blood glucose concentration would be better to be $<200$ $\mathrm{mg} / \mathrm{dl}$ to avoid adverse effects of hyperglycemia [13].

\section{History of Intensive Insulin Therapy}

The first randomized controlled trial (RCT) to assess the risks and benefits of intensive insulin therapy (IIT) (target blood glucose concentration: $80-110 \mathrm{mg} / \mathrm{dl}$ ) compared with those of conventional insulin therapy (target blood glucose concentration: $180-200 \mathrm{mg} / \mathrm{dl}$ ) was conducted by Van den Berghe et al. [14]. In that RCT, IIT significantly reduced the rate of hospital

(c) This is an open-access article distributed under the terms of the Creative Commons Attribution Non-Commercial License (http://creativecommons.org/ licenses/by-nc/4.0/), which permits unrestricted non-commercial use, distribution, and reproduction in any medium, provided the original work is properly cited. 
mortality ( $34 \%$ relative reduction). The second trial by the same investigators showed that mortality rate was not significantly reduced by IIT [15]. When the datasets of these two RCTs were combined, the mortality rates were $20.4 \%$ with IIT and $23.6 \%$ with conventional therapy [16].

More intensive glycemic control was widely recommended following those two studies [17]. However, a more cautious approach has also been recommended, and there are concerns about the widespread adoption of intensive glycemic control [13].

The GLUCONTROL trial, a multicenter RCT (1,078 patients from 21 intensive care unit [ICUs] in Europe) [18], was stopped early due to a high incidence of protocol violations. The GLUCONTROL trial showed that IIT increased the rate of hypoglycemia (IIT vs conventional: $8.7 \%$ vs $2.7 \%, \mathrm{P}<0.0001$ ) with no significant difference in ICU mortality rates (17.2\% vs $15.3 \%, \mathrm{P}$ $=0.41$ ). The VISEP (Efficacy of Volume Substitution and Insulin Therapy in Severe Sepsis) study was also a multicenter RCT (18 ICUs in Germany) conducted in patients with severe sepsis [19]. The VISEP trial was also stopped early because patients received IIT had a significantly higher risk of hypoglycemia without a beneficial effect on 90 -days mortality (39.7\% vs $35.4 \%, \mathrm{P}=0.31$ ). In the Normoglycemia in Intensive Care Evaluation-Survival Using Glucose Algorithm Regulation (NICE-SUGAR) trial conducted in 6104 critically ill patients, IIT significantly increased 90-day mortality compared with the effect of conventional treatment (IIT vs conventional: $27.5 \%$ vs $24.9 \%, \mathrm{P}=0.02$ ) [1].

In 2010, Friedrich et al. [20] reported the results of a systematic review that showed no effect of IIT on mortality in critically ill patients (surgical cohort: risk ratio $=0.85, \mathrm{P}=0.11$; medical cohort: risk ratio $=1.02, \mathrm{P}=0.61$ ). Similarly, other meta-analyses [21-23] show that IIT may not reduce mortality and may increase the risk of hypoglycemia in acutely ill patients.

\section{Optimal Target for Acute Glycemic Control}

After the publications of NICE-SUGAR trial and subsequent meta-analyses, several clinical guidelines stopped recommending IIT, including the Surviving Sepsis Campaign [24]. However, the optimal target of acute glycemic control remains unclear, since there have been few RCTs to compare the target of blood glucose concentrations of 144-180 mg/dl with $110-144 \mathrm{mg} /$ $\mathrm{dl}$ or $>180 \mathrm{mg} / \mathrm{dl}$ [25]. Accordingly, some guidelines recommend commencing insulin administration at a blood glucose concentrations of $>180 \mathrm{mg} / \mathrm{dl}$ [24], whereas other guidelines recommend starting insulin administration at a blood glucose

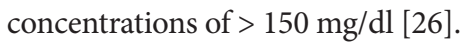

Recently, we conducted a network meta-analysis $(18,098$ patients from $35 \mathrm{RCTs}$ ) to determine the optimal target in acute illness [25]. We showed that there were no significant differ- ences in the risk of mortality and infection among four blood glucose ranges $(<110,110-144,144-180$ and $>180 \mathrm{mg} / \mathrm{dl})$. Blood glucose concentrations of $<110 \mathrm{mg} / \mathrm{dl}$ and $110-144 \mathrm{mg} /$ $\mathrm{dl}$ were associated with greater risk of hypoglycemia than were blood glucose concentrations of 144-180 mg/dl and > $180 \mathrm{mg} /$ dl. These findings were consistent with the results of a network meta-analysis by Yamada et al. [27].

Although not conclusive, the results of the network metaanalysis showed that a blood glucose target of $144-180 \mathrm{mg} / \mathrm{dl}$ might decrease the risk of hypoglycemia and death compared with a target of $110-144 \mathrm{mg} / \mathrm{dl}$.

\section{Impact of Hypoglycemia}

The incidence of severe hypoglycemia (defined as a blood glucose concentration $\leq 40 \mathrm{mg} / \mathrm{dl}$ ) was significantly higher in patients with IIT (relative risk = 13.7) in the NICE-SUGAR trial [1]. Although there have been studies showing a significant association of hypoglycemia with worsened outcomes, no study has confirmed a causal link between hypoglycemia due to IIT and increased mortality.

We conducted a retrospective observational study to determine whether mild or moderate hypoglycemia is independently associated with an increased risk of death in acutely ill patients [28]. Of the 4,946 patients studied, 1,109 (22.4\%) had hypoglycemia; the hospital mortality rate of those patients was $36.6 \%$, whereas it was $19.7 \%$ in patients without hypoglycemia $(\mathrm{P}<$ 0.001). Additionally, mortality increased significantly according to the severity of hypoglycemia $(\mathrm{P}<0.001)$. Even after adjustment for possible confounders, hypoglycemia was independently associated with an increased risk of mortality including all-cause mortality, cardiovascular events related mortality and infectious disease related mortality.

Although the severity of hypoglycemia may be just a marker of the severity of illness [29], hypoglycemia itself might be harmful for acutely ill patients [13]. For example, hypoglycemia might be biologically toxic by inducing neuroglycopenia [30], increasing the systemic inflammatory response [31], causing cerebral vasodilatation [32], impairing sympathetic nervous system responsiveness [33], inhibiting the corticosteroid response to stress [34], or by mechanisms that have yet to be determined. Thus, the available literature may suggest that even mild hypoglycemia should be avoided in acutely ill patients [35].

Several studies have revealed risk factors for hypoglycemia including diabetes mellitus, septic shock, use of mechanical ventilation, use of inotropic support, renal insufficiency, high severity of illness, and use of insulin [36-38]. Therefore, we suggest that all acutely ill patients treated with insulin should be considered at risk for hypoglycemia. 


\section{Devices Used to Measure Blood Glucose}

It is relevant to prevent hyperglycemia or hypoglycemia during acute illness. It is common to use an arterial blood gas (ABG) analyzers and glucometers to measure blood glucose concentrations in critically ill patients. We conducted a systematic review to compare blood glucose concentrations measured by using an ABG and a glucometers with those measured by a central laboratory machine in acutely ill adult patients [39]. In that systematic review, we found that blood glucose measurements of arterial blood using an ABG or a glucometer were significantly more accurate than measurements of capillary blood using a glucometer. Moreover, blood glucose measurements of arterial blood by an ABG tended to be more accurate than those by a glucometer. The risk of errors in measurement by these devices was also higher in the hypoglycemic range, when blood glucose concentration was $<81 \mathrm{mg} / \mathrm{dl}$. Unstable hemodynamics (as evidenced by edema or the use of a vasopressor) combined with the administration of insulin was also associated with an increased risk of error in measurements using a glucometer [39].

Based on these findings, blood glucose monitoring of arterial or venous blood with a glucometer or ABG analyzer is superior to monitoring capillary blood with a glucometer. Nonetheless, we should note that there are large variations in accuracy among devices. Thus, measurement of blood glucose has not reached a sufficient reliability for providing IIT in critically ill patients [39].

\section{Acute Glycemic Control in Critically III Diabetic Patients}

The current criteria for the diagnosis of diabetes mellitus (DM) are based on methods certified by the National Glycohemoglobin Standardization Program. These criteria include a fasting plasma glucose concentration $>126 \mathrm{mg} / \mathrm{dl}$, a random plasma glucose concentration $\geq 200 \mathrm{mg} / \mathrm{dl}$, and a hemoglobin A1c (HbA1c) level $\geq 6.5 \%$ [40]. Since, because acute hyperglycemia is common in critically ill patients even without the presence of diabetes, measurement of HbAlc level at admission to the ICU may be useful for identifying undiagnosed diabetes $[13,41]$.

We have reported that there is a significant interaction between the presence of DM and the association of hyperglycemia with adverse outcomes [42]. Patients with DM had a lower odds ratio of death at all levels of hyperglycemia than did non-diabetic patients, being consistent with results of other studies [43-47]. We have also demonstrated that there is a significant interaction between premorbid hyperglycemia (HbAlc level > 7\%) and the association of hyperglycemia with risk of death [48]. A study by Plummer et al. [49] showed that hyperglycemia was associated with a higher mortality rate in non-diabetic patients with acute hyperglycemia and in diabetic patients with $<7 \%$ of $\mathrm{HbAlc}$ level. However, in diabetic patients with $>7 \%$ of a HbAlc level, hyperglycemia was not associated with mortality. Furthermore, we conducted a multicenter observational study to assess the interaction between premorbid glycemic control and the association of acute hypoglycemia with subsequent hospital mortality in acutely ill patients [50]. In that study, chronic premorbid hyperglycemia increased the incidence of hypoglycemia and modified the relationship of acute hypoglycemia with mortality. Furthermore, the severity of premorbid hyperglycemia was directly proportional to hospital mortality in patients with acute hypoglycemia.

This phenomenon might be explained by the biological adjustment to pre-existing hyperglycemia and low glycemic variability. Thus, blood glucose concentrations that are considered to be desirable for non-diabetic ICU patients might be undesirable for ICU patients with diabetes. Moreover, the optimal blood glucose concentration might be higher in critically ill diabetic patients $[13,41]$. This hypothesis is supported by the results of a study by Van den Berghe et al. [16] showing that diabetic patients did not benefit from IIT. Further study is necessary to determine optimal blood glucose concentrations in acutely ill patients with premorbid hyperglycemia.

\section{Conclusions}

During the past two decades, a number of studies have been carried out to determine optimal acute glycemic control. The results of past studies suggest that blood glucose concentrations should be maintained between 144 and $180 \mathrm{mg} / \mathrm{dl}$. The results also indicate that it is also necessary to avoid even mild hypoglycemia with careful monitoring. Because acutely ill patients receiving insulin infusion are at higher risk for hypoglycemia, reliable devices for measuring blood glucose concentrations, such as an ABG, should be used frequently. Moreover, acute glycemic control in patients with premorbid hyperglycemia is a novel issue for which further study is required.

\section{ORCID}

Moritoki Egi, https://orcid.org/0000-0002-0099-3060

Nana Furushima, https://orcid.org/0000-0002-2759-158X

Shohei Makino, https://orcid.org/0000-0001-5495-0288

Satoshi Mizobuchi, https://orcid.org/0000-0003-2059-3272 


\section{References}

1. NICE-SUGAR Study Investigators, Finfer S, Chittock DR, Su SY, Blair D, Foster D, et al. Intensive versus conventional glucose control in critically ill patients. N Engl J Med 2009; 360: 1283-97.

2. Mizock BA. Alterations in carbohydrate metabolism during stress: a review of the literature. Am J Med 1995; 98: 75-84.

3. McCowen KC, Malhotra A, Bistrian BR. Stress-induced hyperglycemia. Crit Care Clin 2001; 17: 107-24.

4. Khaodhiar L, McCowen K, Bistrian B. Perioperative hyperglycemia, infection or risk? Curr Opin Clin Nutr Metab Care 1999; 2: 79-82.

5. Robinson LE, van Soeren MH. Insulin resistance and hyperglycemia in critical illness: role of insulin in glycemic control. AACN Clin Issues 2004; 15: 45-62.

6. Gearhart MM, Parbhoo SK. Hyperglycemia in the critically ill patient. AACN Clin Issues 2006; 17: 50-5.

7. Finney SJ, Zekveld C, Elia A, Evans TW. Glucose control and mortality in critically ill patients. JAMA 2003; 290: 2041-7.

8. Laird AM, Miller PR, Kilgo PD, Meredith JW, Chang MC. Relationship of early hyperglycemia to mortality in trauma patients. J Trauma 2004; 56: 1058-62.

9. Christiansen C, Toft P, Jørgensen HS, Andersen SK, Tønnesen E. Hyperglycaemia and mortality in critically ill patients. A prospective study. Intensive Care Med 2004; 30: 1685-8.

10. Suleiman M, Hammerman H, Boulos M, Kapeliovich MR, Suleiman A, Agmon Y, et al. Fasting glucose is an important independent risk factor for 30-day mortality in patients with acute myocardial infarction: a prospective study. Circulation 2005; 111: 754-60.

11. Badjatia N, Topcuoglu MA, Buonanno FS, Smith EE, Nogueira RG, Rordorf GA, et al. Relationship between hyperglycemia and symptomatic vasospasm after subarachnoid hemorrhage. Crit Care Med 2005; 33: 1603-9.

12. Choi JJ, Kim HS, Lee KC, Hur H, Jo YY. Prediction of in-hospital mortality and morbidity using high-sensitivity C-reactive protein after burr hole craniostomy. J Anesth 2016; 30: 956-60.

13. Egi M, Finfer S, Bellomo R. Glycemic control in the ICU. Chest 2011; 140: 212-20.

14. Van den Berghe G, Wouters P, Weekers F, Verwaest C, Bruyninckx F, Schetz M, et al. Intensive insulin therapy in critically ill patients. N Engl J Med 2001; 345: 1359-67.

15. Van den Berghe G, Wilmer A, Hermans G, Meersseman W, Wouters PJ, Milants I, et al. Intensive insulin therapy in the medical ICU. N Engl J Med 2006; 354: 449-61.

16. Van den Berghe G, Wilmer A, Milants I, Wouters PJ, Bouckaert B, Bruyninckx F, et al. Intensive insulin therapy in mixed medical/surgical intensive care units: benefit versus harm. Diabetes 2006; 55: 3151-9.

17. Dellinger RP, Levy MM, Carlet JM, Bion J, Parker MM, Jaeschke R, et al. Surviving Sepsis Campaign: international guidelines for management of severe sepsis and septic shock: 2008. Crit Care Med 2008; 36: 296-327.

18. Preiser JC, Devos P, Ruiz-Santana S, Mélot C, Annane D, Groeneveld J, et al. A prospective randomised multi-centre controlled trial on tight glucose control by intensive insulin therapy in adult intensive care units: the Glucontrol study. Intensive Care Med 2009; 35: 1738-48.

19. Brunkhorst FM, Engel C, Bloos F, Meier-Hellmann A, Ragaller M, Weiler N, et al. Intensive insulin therapy and pentastarch resuscitation in severe sepsis. N Engl J Med 2008; 358: 125-39.

20. Friedrich JO, Chant C, Adhikari NK. Does intensive insulin therapy really reduce mortality in critically ill surgical patients? A reanalysis of meta-analytic data. Crit Care 2010; 14: 324.

21. Wiener RS, Wiener DC, Larson RJ. Benefits and risks of tight glucose control in critically ill adults: a meta-analysis. JAMA 2008; 300: 93344.

22. Griesdale DE, de Souza RJ, van Dam RM, Heyland DK, Cook DJ, Malhotra A, et al. Intensive insulin therapy and mortality among critically ill patients: a meta-analysis including NICE-SUGAR study data. CMAJ 2009; 180: 821-7.

23. Marik PE, Preiser JC. Toward understanding tight glycemic control in the ICU: a systematic review and metaanalysis. Chest 2010; 137: 54451.

24. Rhodes A, Evans LE, Alhazzani W, Levy MM, Antonelli M, Ferrer R, et al. Surviving Sepsis Campaign: international guidelines for management of sepsis and septic shock: 2016. Crit Care Med 2017; 45: 486-552.

25. Yatabe T, Inoue S, Sakaguchi M, Egi M. The optimal target for acute glycemic control in critically ill patients: a network meta-analysis. Intensive Care Med 2017; 43: 16-28.

26. Jacobi J, Bircher N, Krinsley J, Agus M, Braithwaite SS, Deutschman C, et al. Guidelines for the use of an insulin infusion for the management of hyperglycemia in critically ill patients. Crit Care Med 2012; 40: 3251-76.

27. Yamada T, Shojima N, Noma H, Yamauchi T, Kadowaki T. Glycemic control, mortality, and hypoglycemia in critically ill patients: a systematic review and network meta-analysis of randomized controlled trials. Intensive Care Med 2017; 43: 1-15.

28. Egi M, Bellomo R, Stachowski E, French CJ, Hart GK, Taori G, et al. Hypoglycemia and outcome in critically ill patients. Mayo Clin Proc 2010; 85: 217-24.

29. Vriesendorp TM, DeVries JH, van Santen S, Moeniralam HS, de Jonge E, Roos YB, et al. Evaluation of short-term consequences of hypoglycemia in an intensive care unit. Crit Care Med 2006; 34: 2714-8.

30. Schlenk F, Graetz D, Nagel A, Schmidt M, Sarrafzadeh AS. Insulin-related decrease in cerebral glucose despite normoglycemia in aneurysmal subarachnoid hemorrhage. Crit Care 2008; 12: R9. 
31. Dotson S, Freeman R, Failing HJ, Adler GK. Hypoglycemia increases serum interleukin-6 levels in healthy men and women. Diabetes Care 2008; 31: 1222-3.

32. Diéguez G, Fernández N, García JL, García-Villalón AL, Monge L, Gomez B. Role of nitric oxide in the effects of hypoglycemia on the cerebral circulation in awake goats. Eur J Pharmacol 1997; 330: 185-93.

33. Herlein JA, Morgan DA, Phillips BG, Haynes WG, Sivitz WI. Antecedent hypoglycemia, catecholamine depletion, and subsequent sympathetic neural responses. Endocrinology 2006; 147: 2781-8.

34. Keller-Wood ME, Shinsako J, Dallman MF. Inhibition of the adrenocorticotropin and corticosteroid responses to hypoglycemia after prior stress. Endocrinology 1983; 113: 491-6.

35. Bellomo R, Egi M. What is a NICE-SUGAR for patients in the intensive care unit? Mayo Clin Proc 2009; 84: 400-2.

36. Krinsley JS, Grover A. Severe hypoglycemia in critically ill patients: risk factors and outcomes. Crit Care Med 2007; 35: $2262-7$.

37. Arabi YM, Tamim HM, Rishu AH. Hypoglycemia with intensive insulin therapy in critically ill patients: predisposing factors and association with mortality. Crit Care Med 2009; 37: 2536-44.

38. Vriesendorp TM, van Santen S, DeVries JH, de Jonge E, Rosendaal FR, Schultz MJ, et al. Predisposing factors for hypoglycemia in the intensive care unit. Crit Care Med 2006; 34: 96-101.

39. Inoue S, Egi M, Kotani J, Morita K. Accuracy of blood-glucose measurements using glucose meters and arterial blood gas analyzers in critically ill adult patients: systematic review. Crit Care 2013; 17: R48.

40. American Diabetes Association. Standards of medical care in diabetes-2017 abridged for primary care providers. Clin Diabetes 2017; 35: $5-26$.

41. Marik PE, Egi M. Treatment thresholds for hyperglycemia in critically ill patients with and without diabetes. Intensive Care Med 2014; 40: 1049-51.

42. Egi M, Bellomo R, Stachowski E, French CJ, Hart GK, Hegarty C, et al. Blood glucose concentration and outcome of critical illness: the impact of diabetes. Crit Care Med 2008; 36: 2249-55.

43. Rady MY, Johnson DJ, Patel BM, Larson JS, Helmers RA. Influence of individual characteristics on outcome of glycemic control in intensive care unit patients with or without diabetes mellitus. Mayo Clin Proc 2005; 80: 1558-67.

44. Krinsley JS. Glycemic control, diabetic status, and mortality in a heterogeneous population of critically ill patients before and during the era of intensive glycemic management: six and one-half years experience at a university-affiliated community hospital. Semin Thorac Cardiovasc Surg 2006; 18: 317-25.

45. Whitcomb BW, Pradhan EK, Pittas AG, Roghmann MC, Perencevich EN. Impact of admission hyperglycemia on hospital mortality in various intensive care unit populations. Crit Care Med 2005; 33: 2772-7.

46. Falciglia M, Freyberg RW, Almenoff PL, D'Alessio DA, Render ML. Hyperglycemia-related mortality in critically ill patients varies with admission diagnosis. Crit Care Med 2009; 37: 3001-9.

47. Umpierrez GE, Isaacs SD, Bazargan N, You X, Thaler LM, Kitabchi AE. Hyperglycemia: an independent marker of in-hospital mortality in patients with undiagnosed diabetes. J Clin Endocrinol Metab 2002; 87: 978-82.

48. Egi M, Bellomo R, Stachowski E, French CJ, Hart GK, Taori G, et al. The interaction of chronic and acute glycemia with mortality in critically ill patients with diabetes. Crit Care Med 2011; 39: 105-11.

49. Plummer MP, Bellomo R, Cousins CE, Annink CE, Sundararajan K, Reddi BA, et al. Dysglycaemia in the critically ill and the interaction of chronic and acute glycaemia with mortality. Intensive Care Med 2014; 40: 973-80.

50. Egi M, Krinsley JS, Maurer P, Amin DN, Kanazawa T, Ghandi S, et al. Pre-morbid glycemic control modifies the interaction between acute hypoglycemia and mortality. Intensive Care Med 2016; 42: 562-71. 